\title{
A Threshold Interpretation of the Ratio-Form Contest Success Function*
}

\author{
Jeremy Petranka
}

Created: October 2009, Latest Revision: March 2010

\begin{abstract}
Ratio-form contest success functions have been widely used due to their appealing axiomatic properties. Existing microfoundational models offer additional justifications for their use in specific economic applications. I propose a new structure under which a ratio-form contest success function can be derived as a limit result using an underlying contest with multiple rounds and threshold success levels. This model generalizes the stochastic equivalence of ratio-form contest success functions and patent race games, allowing greater flexibility in the underlying structural interpretation. I additionally formulate a spatial interpretation of the model and apply the general structure to existing models of conflict.
\end{abstract}

Contest success functions have been widely applied to many economic applications involving uncertain conflict. Finding uses in standard military engagement (Hirshleifer, 1988; Baker, 2003), electoral campaigning (Snyder, 1989; Skaperdas and Grofman, 1995), litigation behavior (Katz, 1988; Farmer and Pecorino, 1999), and numerous other applications, contest success functions have allowed tractable predictions to inherently inconclusive scenarios.

Formally, consider a contest with $n$ players in which each player, $i \in\{1 \ldots n\}$, exerts effort level, $x_{i} \cdot{ }^{1}$ A contest success function (CSF) is defined as

$$
\mathbb{P}: \operatorname{dom}(\vec{x}) \rightarrow[0,1]^{n} \text { such that } \sum_{i=1}^{n} \mathbb{P}_{i}=1, \frac{\partial \mathbb{P}_{i}}{\partial x_{i}}>0 \text {, and } \frac{\partial \mathbb{P}_{i}}{\partial x_{j}}<0 .
$$

Thus, a contest success function maps a player's effort level into his probability of winning the contest. $^{2}$ Foremost of the class of CSF's is the "ratio" form, ${ }^{3}$ which proposes

$$
\mathbb{P}_{i}=\frac{f_{i}\left(x_{i}\right)}{\sum_{l=1}^{n} f_{l}\left(x_{l}\right)}
$$

*I thank Gary Biglaiser, Sergio Parreiras, Matthew Baker, Peter Norman, and seminar participants at UNCChapel Hill, ANU, and UT-Dallas for their valuable comments and suggestions.

${ }^{1} x_{i}$ can be interpreted as actual effort level, campaign expenditures, military expenditures, etc.

${ }^{2}$ Instead of the probability of winning a winner-take-all contest, the CSF can also be interpreted as the share of a prize that is split among the players.

${ }^{3}$ Alternatively referred to as the logit or additive form. 
where the effectivity functions, $f_{i}\left(x_{i}\right), i \in\{1, \ldots, n\}$, map individual efforts into the effective "output" entering the specification in Eqn. 1. The ratio form includes the seminal rent-seeking CSF of Tullock (1980) where $f_{i}(x)=f_{j}(x) \equiv x^{r}$ and the logistic-form proposed by Hirshleifer (1989) where $f_{i}(x)=f_{j}(x) \equiv \exp (k x)$.

Until very recently, the use of CSF's tended to be justified in one of two ways. ${ }^{4}$ The first approach leaves unexplained the microfoundations of the function, but instead appeals to its axiomatic properties. Skaperdas (1996), Kooreman and Schoonbeek (1997), Clark and Riis (1998), and Rai and Sarin (2009) have all shown that under various intuitive conditions, specific forms of the CSF are necessary. Being inherently normative, this approach leaves unanswered questions such as why a particular effectivity function should be used in the class of ratio-form CSF's. Clark and Riis (1998), for instance, show that under certain assumptions, the effectivity function must be of the form, $f_{i}\left(x_{i}\right)=\alpha_{i} x_{i}^{r}$ where $r>0$ and $\alpha_{i}>0$. However, as Perez-Castrillo and Verdier (1992) and Baye et al. (1994) demonstrate, the specific value of $r$ can result in drastically different equilibria.

Alternatively, Katz (1988), Clark and Riis (1996), and Fu and Lu (2008) follow the random utility framework pioneered by McFadden $(1973,1974)$ in which a contest administrator is assumed to have preferences over noisy effort levels. The noise enters additively and is assumed to follow the extreme value distribution. $\mathrm{As} \mathrm{Fu}$ and $\mathrm{Lu}$ (2008) recognize, this can imply an underlying ranking system in which the best outcome is submitted to the contest administrator. ${ }^{5}$ In cases where the "best outcome" is the sole criteria for victory and the normalized error terms have units of logoutput, this approach is highly warranted. However, in many scenarios such as military conflicts, a natural analogue is difficult to construct.

I offer an alternative microfoundation in which the limit of a player's probability of winning a "threshold" contest is stochastically equivalent to the ratio-form conflict success function. ${ }^{6}$ In particular, I propose a game in which players can exert effort to increase their probability of successfully "hitting a target", which is specific to the contest in question. When the number of targets hit in a specified period surpasses an exogenous threshold, the player can win the full contest. The threshold can be in two forms. First, it can be an exogenous absolute threshold in which the first player to surpass the threshold can win the contest. In this interpretation, the game is most like a patent race as specified by Baye and Hoppe (2003). Alternatively, the threshold can measure how much more successful a player must be than his opponents to be able to win the contest. In this interpretation, the game is most like competition during an evaluation period. In both cases, I derive a discrete and continuous form of the threshold game.

In a paper in the same spirit as mine, Corchón and Dahm (2008) offer two alternate microfoundational approaches to modeling CSF's. The first approach requires a contest administrator about whom the players have incomplete information. In economic scenarios in which a contest administrator does not exist, an alternate justification is needed. In addition, when more than two players compete, the ratio form cannot be obtained when a single crossing property is assumed. Their sec-

\footnotetext{
${ }^{4}$ I am excluding a discussion of Tullock's $(1975,1980)$ "lottery" which is incapable of explaining irrational probabilities and was seemingly derived for purely illustrative purposes.

${ }^{5}$ Specifically, when the contest administrator is concerned with log-output. If the contest administrator is concerned with output, the equivalent interpretation implies a strictly logistic CSF.

${ }^{6}$ This structure does not address non-ratio-form CSF's, such as that used in Che and Gale (2000).
} 
ond approach, which is extremely novel, finds that when players bargain over shares of a prize, each player has a bargaining weight of $f_{i}\left(x_{i}\right)$, and the disagreement point is $\vec{d}=\overrightarrow{0}$, then the ratio-form CSF specified in Eqn. 1 is the Nash-bargaining solution. Thus, in scenarios where the good is divisible, ${ }^{7}$ both players are willing to bargain, and bargaining is necessary to receive utility, Corchón and Dahm's (2008) microfoundations seem highly appropriate from a positive perspective.

I focus on scenarios, especially those having elements of conflict, that do not admit these assumptions. In a military conflict between countries, for instance, the disagreement point is not a zero share of the contested zone, but instead the status-quo land share. More generally, conflict scenarios tend to not involve players bargaining over the share of the prize, but instead involve players trying to surpass a threshold necessary for complete victory. In legal conflicts, lawyers try to convince the jury, at which point additional effort is unnecessary and total victory is achieved. In military conflicts, countries attempt to destroy tactical targets to induce surrender. In political conflicts, lobbyists try to convince politicians to vote for their specific policy.

The paper is structured as followed. In Section 1, I specify a discrete conflict game using an absolute threshold and show it induces the ratio-form CSF. In section 2, I extend this model to a continuous game. In Section 3, I specify a discrete game with a relative threshold and show it, too, induces the ratio-form CSF. In Section 4, I extend this model to a continuous game. In Section 5, I offer a spatial interpretation of the proposed models. In Section 6, I apply this model to specific examples in the literature. In Section 7, I offer a caveat to using this method. In Section 8, I conclude.

\section{Discrete Model with Absolute Threshold}

\section{$1.1 \quad$ Model}

In the following model, players compete in a series of rounds. Within each round, each player attempts to hit a target during each turn of the round. If, within the round, a player is the first to surpass an absolute threshold of successful hits, he has the ability to win the contest. If no player surpasses the threshold, the number of successful hits "resets", and a new round is played.

Formally, let $N=\{1,2, \ldots, n\}$ be the set of players who may participate in a contest. The contest consists of (potentially) multiple rounds, with each round having $t \in \mathbb{Z}^{+}$turns. The rules are as follows:

1. For every turn in a round, every player "makes an attempt". Player $i$ makes a successful attempt with probability

$$
P_{i} \equiv g_{i}\left(x_{i}\right) \delta
$$

$g_{i}\left(x_{i}\right)$, Player $i$ 's precision function, captures the technology available to the player to increase his likelihood of making a successful attempt. This function should be specific to the game in question and must map all possible effort levels, $x_{i}$, into $\left[0, \frac{1}{\delta}\right]$ with $\frac{\partial g_{i}}{\partial x_{i}}>0$.

\footnotetext{
${ }^{7}$ Or, less likely, both parties can agree to bargain over probabilities of success.
} 
$\delta>0$, the technological boundary, captures the technical/situational difficulties in making a successful attempt given the nature of the conflict. The results of the paper rely on the limit as $\delta$ approaches zero and are thus not applicable to conflict situations in which minimal effort can result in success with any reasonable certainty.

When developing an interpretation for the underlying structure, it should be noted the separability of $P_{i}$ is crucial for the results.

2. A player is said to have reached his threshold potential if, during any turn in the round, he is the first to achieve his $m$ th successful hit. If more than one player achieves his $m$ th successful hit during the same turn, each successful player reaches his threshold potential with probability $\frac{1}{n}$. If no successful player reaches his threshold potential, the round ends and the

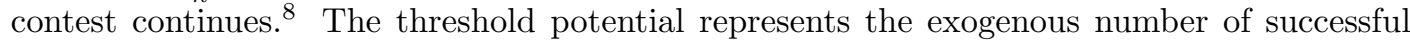
attempts required to have a possibility of winning the contest.

3. After the round is complete, if any player reaches the threshold potential, he wins the contest with probability $\alpha_{i} \in(0,1]$. This probability incorporates personal characteristics of the individual players.

4. If no player wins at the end of the round, a new round is played.

Thus, the underlying contest is one in which the players attempt to reach a success threshold, and they can affect their probability of success through their choice of effort. While the fact that successful attempts in a given round do not transfer to future rounds will be crucial for the results, in many games this requirement is natural. In a military conflict, for instance, attacks normally come in coordinated surges. If, during a surge, enough tactical targets are destroyed, surrender becomes likely. If the opponent can "wait it out", he can regroup, rebuild, and the war effectively begins anew. 9

It should be noted that not all elements of the model are needed for every economic application and some elements of the model can be interchanged with others depending on the scenario. As will be shown, the threshold potential, $m$, and the precision function, $g_{i}\left(x_{i}\right)$, can be adjusted to ensure the precision function has reasonable returns to scale. Also, note if $\alpha_{i}=1$ for each player and $m=t=1$, the contest reduces to a race in which the first player to have a successful attempt wins.

\footnotetext{
${ }^{8}$ This specific tie-breaking rule is used only for ease of notation. The exact rule is inconsequential, as $\lim \delta \rightarrow 0$ implies the probability of two players each achieving his $m$ th successful hit in a turn is dominated by the probability of only one player achieving the threshold.

${ }^{9}$ Consider the U.S. difficulty in dismantling Al Qaeda. According to the 9/11 Commission (2004), in response to the August 7, 1998 embassy attacks, U.S. forces launched Tomahawk missiles on August 20, 1998 at suspected Bin Ladin camps. The strikes are believe to have missed Bin Ladin by a few hours, at which point the surge in military activity ceased. Later, on December 20, 1998, intelligence reported that Bin Ladin was in a location heavily populated by civilians. On the decision to not strike, a lower-level official stated "We should have done it...We may well come to regret the decision not to go ahead". If either of these attempts at Al Qaeda's prime tactical target were successful, it could be argued that the war would have ended. By missing the target, the war continued tactically unchanged.
} 


\subsection{Results}

I now show that under the discrete model with absolute threshold described in Section 1.1, the limit as the technical boundary, $\delta$, approaches zero of the probability a given player wins the contest equals the ratio contest success function specified by Eqn. 1.

Lemma 1. Define $P_{i}^{W}$ as the probability that Player $i$ wins a round. With $t$ turns in a round and a threshold potential of $m$,

$$
\begin{array}{r}
P_{i}^{W}=\alpha_{i} \sum_{h=m}^{t}\left(\begin{array}{c}
h-1 \\
m-1
\end{array}\right) P_{i}^{m}\left(1-P_{i}\right)^{h-m}\left[\prod_{j \in N \backslash i}\left(1-\sum_{k=m}^{h}\left(\begin{array}{c}
k-1 \\
m-1
\end{array}\right) P_{j}^{m}\left(1-P_{j}\right)^{k-m}\right)\right. \\
\left.+\sum_{j \in N \backslash i} \frac{1}{n}\left(\begin{array}{c}
h-1 \\
m-1
\end{array}\right) P_{j}^{m}\left(1-P_{j}\right)^{h-m}\right]
\end{array}
$$

Proof Define $\rho \in N$ as the player who first reaches the threshold potential. We will first determine the probability that $\rho=i$, then determine Player $i$ 's probability of winning the round by noting that

$$
\begin{aligned}
P_{i}^{W} & =\operatorname{Prob}(\operatorname{Player} i \text { wins a } \operatorname{round} \mid \rho=i) \operatorname{Prob}(\rho=i) \\
& =\alpha_{i} \operatorname{Prob}(\rho=i)
\end{aligned}
$$

Define $\rho_{i}^{j}$ as the event "player $i$ reaches the threshold potential during turn $j$ ". Then

$$
\operatorname{Prob}(\rho=i)=\sum_{h=1}^{t} \operatorname{Prob}\left(\rho_{i}^{h}\right)
$$

Recognizing $\operatorname{Prob}\left(\rho_{i}^{h}\right)=0$ for $h<m$,

$$
\operatorname{Prob}(\rho=i)=\sum_{h=m}^{t} \operatorname{Prob}\left(\rho_{i}^{h}\right)
$$

Define $\Upsilon^{i} \in\{0,1\}^{h}$ as the outcome of Player $i$ 's attempts during the first $h$ turns. $\Upsilon_{r}^{i}=0$ if Player $i$ was not successful in his $r$ th attempt, and $\Upsilon_{r}^{i}=1$ otherwise. Note $\#\left\{\cup_{r=1}^{h}\left\{\Upsilon_{r}^{i} \mid \Upsilon_{r}^{i}=1\right\}\right\}$ is the number of successful attempts by Player $i$ in the first $h$ turns. In addition, define $m_{i}^{h}$ as the event "Player $i$ has his $m$ th successful attempt during turn $h$ ", which, by definition, follows the negative binomial distribution,

$$
\operatorname{Prob}\left(m_{i}^{h}\right)=\left(\begin{array}{c}
h-1 \\
m-1
\end{array}\right) P_{i}^{m}\left(1-P_{i}\right)^{h-m} .
$$

The probability that player $i$ reaches the threshold potential in turn $h$ is then 


$$
\begin{aligned}
& \operatorname{Prob}\left(\rho_{i}^{h}\right) \\
& =\operatorname{Prob}\left(m_{i}^{h} \mid \max _{j \in N \backslash i} \#\left\{\cup_{r=1}^{h}\left\{\Upsilon_{r}^{j} \mid \Upsilon_{r}^{j}=1\right\}\right\}<m\right) \operatorname{Prob}\left(\max _{j \in N \backslash i} \#\left\{\cup_{r=1}^{h}\left\{\Upsilon_{r}^{j} \mid \Upsilon_{r}^{j}=1\right\}\right\}<m\right) \\
& \quad+\sum_{j \in N \backslash i} \frac{1}{n} \operatorname{Prob}\left(m_{i}^{h} \mid m_{j}^{h}\right) \operatorname{Prob}\left(m_{j}^{h}\right) \\
& =\operatorname{Prob}\left(m_{i}^{h}\right) \prod_{j \in N \backslash i}\left(1-\sum_{k=1}^{h} \operatorname{Prob}\left(m_{j}^{k}\right)\right)+\sum_{j \in N \backslash i} \frac{1}{n} \operatorname{Prob}\left(m_{i}^{h}\right) \operatorname{Prob}\left(m_{j}^{k}\right) \\
& =\operatorname{Prob}\left(m_{i}^{h}\right)\left[\prod_{j \in N \backslash i}\left(1-\sum_{k=1}^{h} \operatorname{Prob}\left(m_{j}^{k}\right)\right)+\sum_{j \in N \backslash i} \frac{1}{n} \operatorname{Prob}\left(m_{j}^{k}\right)\right] .
\end{aligned}
$$

Plugging Eqn. (6) into Eqn. (7) and recognizing $\operatorname{Prob}\left(m_{j}^{k}\right)=0$ for $k<m$,

$$
\begin{array}{r}
\operatorname{Prob}\left(\rho_{i}^{h}\right)=\left(\begin{array}{c}
h-1 \\
m-1
\end{array}\right) P_{i}^{m}\left(1-P_{i}\right)^{h-m}\left[\prod_{j \in N \backslash i}\left(1-\sum_{k=m}^{h}\left(\begin{array}{c}
k-1 \\
m-1
\end{array}\right) P_{j}^{m}\left(1-P_{j}\right)^{k-m}\right)\right. \\
\left.+\sum_{j \in N \backslash i} \frac{1}{n}\left(\begin{array}{c}
h-1 \\
m-1
\end{array}\right) P_{j}^{m}\left(1-P_{j}\right)^{h-m}\right]
\end{array}
$$

Combining Eqns. (4), (5), and (8) gives the desired result.

Using Lemma 1, we can now determine the overall probability that Player $i$ wins the contest.

Lemma 2. Define $\mathbb{P}_{i}$ as the probability that Player $i$ wins the contest. With $t$ turns in a round and a threshold potential of $m$,

$$
\begin{aligned}
& \mathbb{P}_{i}= \\
& \alpha_{i} g_{i}\left(x_{i}\right)^{m} \sum_{h=m}^{t}\left(1-g_{i}\left(x_{i}\right) \delta\right)^{h-m}\left[\prod_{j \in N \backslash i}\left(1-\sum_{k=m}^{h}\left(\begin{array}{c}
k-1 \\
m-1
\end{array}\right) g_{j}\left(x_{j}\right)^{m} \delta^{m}\left(1-g_{j}\left(x_{j}\right) \delta\right)^{k-m}\right)\right. \\
& \left.+\sum_{j \in N \backslash i} \frac{1}{n}\left(\begin{array}{c}
h-1 \\
m-1
\end{array}\right) g_{j}\left(x_{j}\right)^{m} \delta^{m}\left(1-g_{j}\left(x_{j}\right) \delta\right)^{h-m}\right] \\
& \sum_{l=1}^{n} \alpha_{l} g_{l}\left(x_{l}\right)^{m} \sum_{h=m}^{t}\left(1-g_{l}\left(x_{l}\right) \delta\right)^{h-m}\left[\prod_{j \in N \backslash l}\left(1-\sum_{k=m}^{h}\left(\begin{array}{c}
k-1 \\
m-1
\end{array}\right) g_{j}\left(x_{j}\right)^{m} \delta^{m}\left(1-g_{j}\left(x_{j}\right) \delta\right)^{k-m}\right)\right. \\
& \left.+\sum_{j \in N \backslash l} \frac{1}{n}\left(\begin{array}{c}
h-1 \\
m-1
\end{array}\right) g_{j}\left(x_{j}\right)^{m} \delta^{m}\left(1-g_{j}\left(x_{j}\right) \delta\right)^{h-m}\right]
\end{aligned}
$$

Proof Note first that if $\sum_{l=1}^{n} P_{l}^{W} \neq 0$ then: ${ }^{10}$

\footnotetext{
${ }^{10}$ Note when $\delta=0$, this condition is violated, causing a discontinuity in the probabilities. I thus focus solely on the limit result, with the reader being advised to consider the necessary interpretive caveats.
} 


$$
\begin{aligned}
\mathbb{P}_{i} & =P_{i}^{W}+\left(1-\sum_{l=1}^{n} P_{l}^{W}\right) P_{i}^{W}+\left(1-\sum_{l=1}^{n} P_{l}^{W}\right)^{2} P_{i}^{W}+\ldots \\
& =\frac{P_{i}^{W}}{1-\left(1-\sum_{l=1}^{n} P_{l}^{W}\right)} \\
& =\frac{P_{i}^{W}}{\sum_{l=1}^{n} P_{l}^{W}}
\end{aligned}
$$

In addition, by substituting Eqn. (3) into Eqn. (9), expanding the $P_{i}$ 's per Eqn. (2), and slightly rearranging,

$$
\begin{aligned}
& \mathbb{P}_{i}= \\
& \begin{array}{r}
\alpha_{i} g_{i}\left(x_{i}\right)^{m} \delta^{m} \sum_{h=m}^{t}\left(1-g_{i}\left(x_{i}\right) \delta\right)^{h-m}\left[\prod_{j \in N \backslash i}\left(1-\sum_{k=m}^{h}\left(\begin{array}{c}
k-1 \\
m-1
\end{array}\right) g_{j}\left(x_{j}\right)^{m} \delta^{m}\left(1-g_{j}\left(x_{j}\right) \delta\right)^{k-m}\right)\right. \\
\left.+\sum_{j \in N \backslash i} \frac{1}{n}\left(\begin{array}{c}
h-1 \\
m-1
\end{array}\right) g_{j}\left(x_{j}\right)^{m} \delta^{m}\left(1-g_{j}\left(x_{j}\right) \delta\right)^{h-m}\right]
\end{array} \\
& \begin{array}{r}
\sum_{l=1}^{n} \alpha_{l} g_{l}\left(x_{l}\right)^{m} \delta^{m} \sum_{h=m}^{t}\left(1-g_{l}\left(x_{l}\right) \delta\right)^{h-m}\left[\prod_{j \in N \backslash l}\left(1-\sum_{k=m}^{h}\left(\begin{array}{c}
k-1 \\
m-1
\end{array}\right) g_{j}\left(x_{j}\right)^{m} \delta^{m}\left(1-g_{j}\left(x_{j}\right) \delta\right)^{k-m}\right)\right. \\
\left.+\sum_{j \in N \backslash l} \frac{1}{n}\left(\begin{array}{c}
h-1 \\
m-1
\end{array}\right) g_{j}\left(x_{j}\right)^{m} \delta^{m}\left(1-g_{j}\left(x_{j}\right) \delta\right)^{h-m}\right]
\end{array}
\end{aligned}
$$

Cancelling the $\delta^{m}$ terms gives the desired result.

Finally, we can use Lemma 2 to prove the first result of the paper.

Theorem 1. Given the underlying model described in Section 1.1, the limit as $\delta$ approaches zero of the probability that Player $i$ wins the contest is the ratio-form contest success function:

$$
\lim _{\delta \rightarrow 0} \mathbb{P}_{i}=\frac{\alpha_{i} g_{i}\left(x_{i}\right)^{m}}{\sum_{l=1}^{n} \alpha_{l} g_{l}\left(x_{l}\right)^{m}} \equiv \frac{f_{i}\left(x_{i}\right)}{\sum_{l=1}^{n} f_{l}\left(x_{l}\right)}
$$

Proof The Theorem is a direct result of taking the limit of $\mathbb{P}_{i}$ as defined in Lemma 2. In particular, 


$$
\begin{aligned}
& \lim _{\delta \rightarrow 0} \mathbb{P}_{i}= \begin{array}{r}
\lim _{\delta \rightarrow 0} \alpha_{i} g_{i}\left(x_{i}\right)^{m} \sum_{h=m}^{t}\left(1-g_{i}\left(x_{i}\right) \delta\right)^{h-m}\left[\prod_{j \in N \backslash i}\left(1-\sum_{k=m}^{h}\left(\begin{array}{c}
k-1 \\
m-1
\end{array}\right) g_{j}\left(x_{j}\right)^{m} \delta^{m}\left(1-g_{j}\left(x_{j}\right) \delta\right)^{k-m}\right)\right. \\
\left.+\sum_{j \in N \backslash i} \frac{1}{n}\left(\begin{array}{c}
h-1 \\
m-1
\end{array}\right) g_{j}\left(x_{j}\right)^{m} \delta^{m}\left(1-g_{j}\left(x_{j}\right) \delta\right)^{h-m}\right]
\end{array} \\
& \begin{array}{l}
\lim _{\delta \rightarrow 0} \sum_{l=1}^{n} \alpha_{l} g_{l}\left(x_{l}\right)^{m} \sum_{h=m}^{t}\left(1-g_{l}\left(x_{l}\right) \delta\right)^{h-m}\left[\prod_{j \in N \backslash l}\left(1-\sum_{k=m}^{h}\left(\begin{array}{c}
k-1 \\
m-1
\end{array}\right) g_{j}\left(x_{j}\right)^{m} \delta^{m}\left(1-g_{j}\left(x_{j}\right) \delta\right)^{k-m}\right)\right. \\
\quad
\end{array} \\
&= \frac{\alpha_{i} g_{i}\left(x_{i}\right)^{m}\left[\prod_{j \in N}\left(\begin{array}{c}
h-1 \\
m-1
\end{array}\right) g_{j}\left(x_{j}\right)^{m} \delta^{m}\left(1-g_{j}\left(x_{j}\right) \delta\right)^{h-m}\right]}{\sum_{l=1}^{n} \alpha_{l} g_{l}\left(x_{l}\right)^{m}\left[\prod_{j \in N \backslash l}(1)+(0)\right]} \\
&=\frac{\alpha_{i} g_{i}\left(x_{i}\right)^{m}}{\sum_{l=1}^{n} \alpha_{l} g_{l}\left(x_{l}\right)^{m}}
\end{aligned}
$$

Intuitively, this result is directly related to the fact that the game is repeated indefinitely. Thus, the probability that no player wins equals zero, even if $\delta$ is very small. The tractability is due to the fact that as $\delta$ approaches zero, the probability of having more than one player reach the threshold is dominated by the probability of having exactly one player reach the threshold.

Note that by setting $\alpha_{i}=1$ for all players and $m=1$,

$$
\lim _{\delta \rightarrow 0} \mathbb{P}_{i}=\frac{g_{i}\left(x_{i}\right)}{\sum_{l=1}^{n} g_{l}\left(x_{l}\right)} .
$$

Thus, when interpreting the model as a patent race in which the first player to innovate wins, the effectivity function, $f_{i}\left(x_{i}\right)$, is equal to the precision function, $g_{i}\left(x_{i}\right)$, and is directly interpreted as the mapping from effort into the probability of having a successful innovation. However, by adjusting the threshold level, $m$, alternate returns to scale of the effectivity function can be justified.

\subsection{Tullock's Rent-Seeking Function}

As an example, consider the seminal rent-seeking function proposed by Tullock $(1980),{ }^{11}$

$$
\mathbb{P}_{i}=\frac{x_{i}^{m}}{\sum_{l=1}^{n} x_{l}^{m}} .
$$

\footnotetext{
${ }^{11}$ In the discrete model with absolute threshold, this assumes $\alpha_{i}=1$ for all players.
} 
Many papers, such as Garfinkel and Skaperdas (2000), explicitly assume $m=1$. In the context of the discrete model with absolute threshold, this can be interpreted as a conflict in which the first player to make a successful attempt wins the contest. Specifically, players can linearly increase their probability of success for any given attempt via $P_{i}=x_{i} \delta$. Under this interpretation, the probability technology displays constant returns to scale, which may not accurately reflect the specifics of the economic application. In Garfinkel and Skaperdas (2000), for instance, this implies the military technology designed to increase precision displays constant returns to scale. If, instead, the game is interpreted as a series of military strikes in which each player requires two hits during any given strike, then the identical CSF implies an underlying technology displaying decreasing returns to scale:

$$
\mathbb{P}_{i}=\frac{x_{i}}{\sum_{l=1}^{n} x_{l}}=\frac{\left(x_{i}^{1 / 2}\right)^{2}}{\sum_{l=1}^{n}\left(x_{l}^{1 / 2}\right)^{2}} .
$$

Thus, by modifying the threshold potential, the effectivity functions can be modeled to display reasonable returns to scale. In addition, the $\alpha_{i}$ 's can be interpreted as the exogenous probability of winning the game once the threshold is fulfilled, or a specification of the effectivity function.

Perhaps more importantly, this microfoundation offers insights into how differing levels of $m$ can be interpreted. In the Tullock form, an increase in $m$ is interpreted as an event that makes, for any given effort levels, the weaker opponent less likely to win the contest. The models presented in this paper offer two reasons this might be the case. First, when $m$ is interpreted as part of the players' precision functions, an increase in $m$ relates to a "scaling" of all the players' abilities. Thus, good players become great, average players become good, etc. Thus, to some extent, the underlying contest can be interpreted as becoming easier for all players. By making the best player great, the likelihood she is the first to hit the threshold increases. Perhaps counterintuitively, a higher level of $m$ can also be interpreted as a more difficult contest. In particular, if $m$ is interpreted as the number of required successes to ensure a victory, then an increase in $m$ implies a greater number of required successes. Intuitively, this is bad for the weaker player since as the contest becomes more difficult, only the best player is likely to win.

\section{Continuous Model with Absolute Threshold}

\section{$2.1 \quad$ Model}

Given that the discrete model can be interpreted as a patent race requiring a threshold number of innovations, it is not surprising that a similar result to Baye and Hoppe (2003) holds, which shows a continuous patent game such as Loury (1979) and Dasgupta and Stiglitz (1980) is strategically equivalent to a contest game incorporating a ratio-form contest success function.

Specifically, players again compete in a series of rounds, each of time duration, $T$. As in the discrete case, players attempt to hit a target throughout the round. If a player is the first to surpass an absolute threshold of successful hits, he has the ability to win the contest. If no player surpasses the threshold, the number of successful hits "resets", and a new round is played.

Formally, let $N=\{1,2, \ldots, n\}$ be the set of players who may participate in a contest. The contest consists of (potentially) multiple rounds, with each round having time duration, $T$. The rules are 
as follows:

1. Throughout each round, every player's number of successes follows a Poisson process. In particular, the time, $t$, at which each sequential independent success occurs is a random variable having exponential density,

$$
P_{i} \equiv g_{i}\left(x_{i}\right) \delta \exp ^{-g_{i}\left(x_{i}\right) \delta t}
$$

Thus, the probability that an individual is successful at or before time $t$ equals

$$
\int_{0}^{t} P_{i} d t=1-\exp ^{-g_{i}\left(x_{i}\right) \delta t}
$$

As before, $g_{i}\left(x_{i}\right)$ is Player $i$ 's precision function and captures the technology available to the player to increase his likelihood of making a successful attempt in a given time period. This function should be specific to the game in question and must map all possible effort levels, $x_{i}$, into $(0, M<\infty]$ with $\frac{\partial g_{i}}{\partial x_{i}}>0 .{ }^{12} \delta>0$ again captures the technical/situational difficulties in making a successful attempt given the nature of the conflict.

2. A player is said to have reached his threshold potential if, at any time during a round, he is the first to achieve his $m$ th successful hit. The threshold potential represents the exogenous number of successful attempts required to have a possibility of winning the contest. As the probability of two players each achieving his $m$ th successful hit at the same instant is zero, any tie-breaking rule can be assumed.

3. After the round is complete, if any player reaches the threshold potential, he wins the contest with probability $\alpha_{i} \in(0,1]$. This probability incorporates personal characteristics of the individual players.

4. If no player wins at the end of the round, a new round is played.

Thus, the underlying contest is essentially the same as the discrete model, but players' effort levels affect the time it takes to achieve a success.

\section{$2.2 \quad$ Results}

I now show that under the continuous model with absolute threshold described in Section 2.1, the limit as the technical boundary, $\delta$, approaches zero of the probability a given player wins the contest equals the ratio contest function specified in Eqn. 1.

\footnotetext{
${ }^{12}$ Note in the continuous case, $g_{i}\left(x_{i}\right)$ 's upper bound need not relate to $\delta$. In particular, while the hazard rate, $g_{i}\left(x_{i}\right) \delta$, has an interpretation of instantaneous conditional probability of success, it is not formally a probability measure. This fact implies Baye and Hoppe's (2003) restriction that the hazard rate in a patent game be defined over $[0,1]$ is not necessary.
} 
Lemma 3. Define $P_{i}^{W}$ as the probability that Player $i$ wins a round. With each round having time duration, $T$, and a threshold potential of $m$,

$$
P_{i}^{W}=\frac{g_{i}\left(x_{i}\right)^{m} \delta^{m}}{(m-1) !} \int_{0}^{T} \exp ^{-g_{i}\left(x_{i}\right) \delta t} t^{m-1} \prod_{j \in N \backslash i} \sum_{h=0}^{m-1} \frac{g_{i}\left(x_{i}\right)^{h} \delta^{h} t^{h}}{h !} d t
$$

Proof Note with the defined underlying Poisson process, the probability density function of achieving $m$ successes follows the $\Gamma\left(m, g_{i}\left(x_{i}\right) \delta\right)$ distribution,

$$
\frac{g_{i}\left(x_{i}\right)^{m} \delta^{m}}{(m-1) !} t^{m-1} \exp ^{-g_{i}\left(x_{i}\right) \delta t}
$$

In addition, note if $X$ is a $\Gamma\left(m, g_{i}\left(x_{i}\right) \delta\right)$ random variable, it has the property ${ }^{13}$

$$
\operatorname{Prob}(X \geq t)=\operatorname{Prob}(Y<m)
$$

where $Y$ is a Poisson $\left(g_{i}\left(x_{i}\right) \delta t\right)$ random variable having

$$
\operatorname{Prob}(Y=h)=\frac{\exp ^{-g_{i}\left(x_{i}\right) \delta t} g_{i}\left(x_{i}\right)^{h} \delta^{h} t^{h}}{h !}
$$

Using Eqns. (11),(12), and (13), the probability that $n-1$ players do not achieve $m$ successes by time $t$ is

$$
\prod_{j \in N \backslash i} \int_{t}^{\infty} \frac{g_{j}\left(x_{j}\right)^{m} \delta^{m}}{(m-1) !} t^{m-1} \exp ^{-g_{j}\left(x_{j}\right) \delta t} d t=\prod_{j \in N \backslash i} \sum_{h=0}^{m-1} \frac{g_{j}\left(x_{j}\right)^{h} \delta^{h} t^{h}}{h !}
$$

Using Eqns. (11) and (14), the probability Player $i$ wins a given round is

$$
P_{i}^{W}=\int_{0}^{T} \frac{g_{i}\left(x_{i}\right)^{m} \delta^{m}}{(m-1) !} \exp ^{-g_{i}\left(x_{i}\right) \delta t} t^{m-1} \prod_{j \in N \backslash i} \sum_{h=0}^{m-1} \frac{g_{i}\left(x_{i}\right)^{h} \delta^{h} t^{h}}{h !} d t .
$$

Slight rearrangement gives the desired result.

Using Lemma 3, we can now determine the overall probability that Player $i$ wins the contest.

Lemma 4. Define $\mathbb{P}_{i}$ as the probability that Player $i$ wins the contest. With each round having time duration, $T$, and a threshold potential of $m$,

$$
\mathbb{P}_{i}=\frac{g_{i}\left(x_{i}\right)^{m} \int_{0}^{T} \exp ^{-g_{i}\left(x_{i}\right) \delta t} t^{m-1} \prod_{j \in N \backslash i} \sum_{h=0}^{m-1} \frac{g_{i}\left(x_{i}\right)^{h} \delta^{h} t^{h}}{h !} d t}{\sum_{l \in N} g_{l}\left(x_{l}\right)^{m} \int_{0}^{T} \exp ^{-g_{l}\left(x_{l}\right) \delta t} t^{m-1} \prod_{j \in N \backslash l} \sum_{h=0}^{m-1} \frac{g_{l}\left(x_{l}\right)^{h} \delta^{h} t^{h}}{h !} d t}
$$

\footnotetext{
${ }^{13}$ Please refer to Casella and Berger (2002) for details.
} 
Proof As in the proof of Lemma 2, note first that if $\sum_{l=1}^{n} P_{l}^{W} \neq 0$ then

$$
\mathbb{P}_{i}=\frac{P_{i}^{W}}{\sum_{l=1}^{n} P_{l}^{W}}
$$

Substituting Eqn. (10) into Eqn. (14) and canceling $\delta^{m}$ and $(m-1)$ ! gives the desired result.

Finally, we can use Lemma 4 to prove the following result of the paper.

Theorem 2. Given the underlying model described in Section 2.1, the limit as $\delta$ approaches zero of the probability that Player $i$ wins the contest is the ratio-form contest success function:

$$
\lim _{\delta \rightarrow 0} \mathbb{P}_{i}=\frac{\alpha_{i} g_{i}\left(x_{i}\right)^{m}}{\sum_{l=1}^{n} \alpha_{l} g_{l}\left(x_{l}\right)^{m}} \equiv \frac{f_{i}\left(x_{i}\right)}{\sum_{l=1}^{n} f_{l}\left(x_{l}\right)}
$$

Proof With $g_{i}\left(x_{i}\right)$ bounded,

$$
\begin{aligned}
& \lim _{\delta \rightarrow 0} \frac{g_{i}\left(x_{i}\right)^{m} \int_{0}^{T} \exp ^{-g_{i}\left(x_{i}\right) \delta t} t^{m-1} \prod_{j \in N \backslash i} \sum_{h=0}^{m-1} \frac{g_{i}\left(x_{i}\right)^{h} \delta^{h} t^{h}}{h !} d t}{\sum_{l \in N} g_{l}\left(x_{l}\right)^{m} \int_{0}^{T} \exp ^{-g_{l}\left(x_{l}\right) \delta t} t^{m-1} \prod_{j \in N \backslash l} \sum_{h=0}^{m-1} \frac{g_{l}\left(x_{l}\right)^{h} \delta^{h} t^{h}}{h !} d t} \\
& \quad=\frac{\lim _{\delta \rightarrow 0} g_{i}\left(x_{i}\right)^{m} \int_{0}^{T} \exp ^{-g_{i}\left(x_{i}\right) \delta t} t^{m-1} \prod_{j \in N \backslash i} \sum_{h=0}^{m-1} \frac{g_{i}\left(x_{i}\right)^{h} \delta^{h} t^{h}}{h !} d t}{\lim _{\delta \rightarrow 0} \sum_{l \in N} g_{l}\left(x_{l}\right)^{m} \int_{0}^{T} \exp ^{-g_{l}\left(x_{l}\right) \delta t} t^{m-1} \prod_{j \in N \backslash l} \sum_{h=0}^{m-1} \frac{g_{l}\left(x_{l}\right)^{h} \delta^{h} t^{h}}{h !} d t}
\end{aligned}
$$

Define $\frac{1}{z} \equiv \delta$ so that

$$
\begin{aligned}
& \lim _{\delta \rightarrow 0} g_{i}\left(x_{i}\right)^{m} \int_{0}^{T} \exp ^{-g_{i}\left(x_{i}\right) \delta t} t^{m-1} \prod_{j \in N \backslash i} \sum_{h=0}^{m-1} \frac{g_{i}\left(x_{i}\right)^{h} \delta^{h} t^{h}}{h !} d t \\
& =\lim _{z \rightarrow \infty} g_{i}\left(x_{i}\right)^{m} \int_{0}^{T} \exp ^{-g_{i}\left(x_{i}\right) \frac{1}{z} t} t^{m-1} \prod_{j \in N \backslash i} \sum_{h=0}^{m-1} \frac{g_{i}\left(x_{i}\right)^{h} \frac{1}{z} t^{h}}{h !} d t
\end{aligned}
$$

Note for all values of $z$,

$$
g_{i}\left(x_{i}\right)^{m} \int_{0}^{T} \exp ^{-g_{i}\left(x_{i}\right) \frac{1}{z} t} t^{m-1} \prod_{j \in N \backslash i} \sum_{h=0}^{m-1} \frac{g_{i}\left(x_{i}\right)^{h} \frac{1^{h}}{z} t^{h}}{h !}
$$

is a real-valued measurable function uniformly bounded by 


$$
g_{i}\left(x_{i}\right)^{m} \int_{0}^{T} \exp ^{-g_{i}\left(x_{i}\right) t} t^{m-1} \prod_{j \in N \backslash i} \sum_{h=0}^{m-1} \frac{g_{i}\left(x_{i}\right)^{h} t^{h}}{h !} .
$$

Thus, the Bounded Convergence Theorem states that

$$
\begin{aligned}
& \lim _{z \rightarrow \infty} g_{i}\left(x_{i}\right)^{m} \int_{0}^{T} \exp ^{-g_{i}\left(x_{i}\right) \frac{1}{z} t} t^{m-1} \prod_{j \in N \backslash i} \sum_{h=0}^{m-1} \frac{g_{i}\left(x_{i}\right)^{h} \frac{1^{h}}{z} t^{h}}{h !} d t \\
& =g_{i}\left(x_{i}\right)^{m} \int_{0}^{T} \lim _{z \rightarrow \infty} \exp ^{-g_{i}\left(x_{i}\right) \frac{1}{z} t} t^{m-1} \prod_{j \in N \backslash i} \sum_{h=0}^{m-1} \frac{g_{i}\left(x_{i}\right)^{h} \frac{1}{z} t^{h}}{h !} d t \\
& =\frac{T^{m} g_{i}\left(x_{i}\right)^{m}}{m}
\end{aligned}
$$

Using identical logic on the denominator of Eqn. (15), canceling the $\frac{T^{m}}{m}$ terms, and combining the above gives the desired result.

Note that when $m=1, T=\infty$, the continuous model with absolute threshold is equivalent to the patent race specified in Baye and Hoppe (2003).

\section{$3 \quad$ Discrete Model with Relative Threshold}

\section{$3.1 \quad$ Model}

In an alternative model, players again compete in a series of rounds and each player attempts to hit a target during each turn of the round. If, at the end of the round, the difference between one player's number of successful hits and the second most successful player's number of successful hits weakly exceeds the threshold potential, that player has the ability to win the contest. If no player surpasses the relative threshold, the number of successful hits "resets", and a new round is played.

Formally, let $N=\{1,2, \ldots, n\}$ be the set of players who may participate in a contest. The contest consists of (potentially) multiple rounds, with each round having $t \in \mathbb{Z}^{+}$turns. The rules are as follows:

1. For every turn in a round, every player "makes an attempt". Player $i$ makes a successful attempt with probability

$$
P_{i} \equiv g_{i}\left(x_{i}\right) \delta
$$

where $g_{i}\left(x_{i}\right)$ and $\delta$ are defined as in Section 1.

2. After the round is complete, a player is said to reach the threshold potential, $m$, if he has $m$ or more successful attempts than the second most successful player during the round. Note this threshold is a relative benchmark representing how much better one player must perform compared to the other players. 
3. After the round is complete, if any player reaches the threshold potential, he wins the contest with probability $\alpha_{i} \in(0,1]$. This probability incorporates personal characteristics of the individual players.

4. If no player wins at the end of the round, a new round is played.

Thus, the underlying contest is one in which the players are competing against each other, attempting to demonstrate superiority in a given round. This model incorporates the concept of an "evaluation period" during which players are appraised. ${ }^{14}$ When appropriate, the threshold level can be interpreted as an explicit satisficing requirement.

When considering potential applications of this model, it is again important to note that successful attempts in a given round can not transfer to future rounds. With a relative threshold, this implies a player who is extremely weak in a given round is not punished at any point in the future as long as two other players in the current round ensure neither exceeds the threshold. Thus, if there is not a natural separation during which previous successes can be "forgotten", this model should be used with caution.

\subsection{Results}

I now show that under the contest described in Section 3.1, the limit as the technical boundary, $\delta$, approaches zero of the probability a given player wins the contest equals the ratio contest success function specified by Eqn. 1.

Lemma 5. Define $P_{i}^{W}$ as the probability that Player $i$ wins a round. With $t$ turns in a round and a threshold potential of $m$,

$$
P_{i}^{W}=\alpha_{i} \sum_{h=m}^{t}\left(\begin{array}{l}
t \\
h
\end{array}\right) P_{i}^{h}\left(1-P_{i}\right)^{t-h}\left[\prod_{j \in N \backslash i}\left[\sum_{k=0}^{h-m}\left(\begin{array}{l}
t \\
k
\end{array}\right) P_{j}^{k}\left(1-P_{j}\right)^{t-k}\right]\right]
$$

Proof Define $\Upsilon^{i} \in\{0,1\}^{t}$ as the outcome of Player $i$ 's attempts in a given round. $\Upsilon_{r}^{i}=1$ if Player $i$ is successful in his $r$ th attempt, and $\Upsilon_{r}^{i}=0$ otherwise. Define the difference between the number of successful attempts made by Player $i$ and the number of successful attempts made by the most successful remaining player as

$$
\Delta_{i} \equiv \#\left\{\cup_{r=1}^{t}\left\{\Upsilon_{r}^{i} \mid \Upsilon_{r}^{i}=1\right\}\right\}-\max _{j \in N \backslash i} \#\left\{\cup_{r=1}^{t}\left\{\Upsilon_{r}^{j} \mid \Upsilon_{r}^{j}=1\right\}\right\}
$$

To determine $P_{i}^{W}$, we will first determine the probability that Player $i$ has $m$ or more successful attempts than the second most successful player, then determine Player $i$ 's probability of winning the round by noting that

\footnotetext{
${ }^{14}$ The results do not change if the "evaluation period" interpretation is discarded but the relative threshold is maintained. Specifically, the same results are achieved if the first player to have $m$ more successful attempts than any other player is said to reach the threshold potential.
} 


$$
\begin{aligned}
P_{i}^{W} & =\operatorname{Prob}\left(\operatorname{Player} i \text { wins a round } \mid \Delta_{i} \geq m\right) \operatorname{Prob}\left(\Delta_{i} \geq m\right) \\
& =\alpha_{i} \operatorname{Prob}\left(\Delta_{i} \geq m\right)
\end{aligned}
$$

Disjointly partitioning the underlying set and using the definition of conditional probabilities, we find the probability that Player $i$ has $m$ or more successful attempts than the second most successful player equals

$$
\begin{aligned}
& \operatorname{Prob}\left(\Delta_{i} \geq m\right)= \\
& \quad \sum_{h=1}^{t} \operatorname{Prob}\left(\#\left\{\cup_{r=1}^{t}\left\{\Upsilon_{r}^{i} \mid \Upsilon_{r}^{i}=1\right\}\right\}=h\right) \operatorname{Prob}\left(\Delta_{i} \geq m \mid \#\left\{\cup_{r=1}^{t}\left\{\Upsilon_{r}^{i} \mid \Upsilon_{r}^{i}=1\right\}\right\}=h\right)
\end{aligned}
$$

or, recognizing $\operatorname{Prob}\left(\Delta_{i} \geq m \mid \#\left\{\cup_{r=1}^{t}\left\{\Upsilon_{r}^{i} \mid \Upsilon_{r}^{i}=1\right\}\right\}=h\right)=0$ when $h<m$

$$
\begin{aligned}
& \operatorname{Prob}\left(\Delta_{i} \geq m\right)= \\
& \quad \sum_{h=m}^{t} \operatorname{Prob}\left(\#\left\{\cup_{r=1}^{t}\left\{\Upsilon_{r}^{i} \mid \Upsilon_{r}^{i}=1\right\}\right\}=h\right) \operatorname{Prob}\left(\Delta_{i} \geq m \mid \#\left\{\cup_{r=1}^{t}\left\{\Upsilon_{r}^{i} \mid \Upsilon_{r}^{i}=1\right\}\right\}=h\right)
\end{aligned}
$$

Using Eqn. 18, further note

$$
\operatorname{Prob}\left(\Delta_{i} \geq m \mid \#\left\{\cup_{r=1}^{t}\left\{\Upsilon_{r}^{i} \mid \Upsilon_{r}^{i}=1\right\}\right\}=h\right) \quad=\operatorname{Prob}\left(h-\max _{j \in N \backslash i} \#\left\{\cup_{r=1}^{t}\left\{\Upsilon_{r}^{j} \mid \Upsilon_{r}^{j}=1\right\}\right\} \geq m\right)
$$

which, after expanding the max term, implies

$$
\operatorname{Prob}\left(\Delta_{i} \geq m \mid \#\left\{\cup_{r=1}^{t}\left\{\Upsilon_{r}^{i} \mid \Upsilon_{r}^{i}=1\right\}\right\}=h\right)=\prod_{j \in N \backslash i} \operatorname{Prob}\left(h-\#\left\{\cup_{r=1}^{t}\left\{\Upsilon_{r}^{j} \mid \Upsilon_{r}^{j}=1\right\}\right\} \geq m\right)
$$

or, rearranging,

$$
\operatorname{Prob}\left(\Delta_{i} \geq m \mid \#\left\{\cup_{r=1}^{t}\left\{\Upsilon_{r}^{i} \mid \Upsilon_{r}^{i}=1\right\}\right\}=h\right)=\prod_{j \in N \backslash i} \operatorname{Prob}\left(\#\left\{\cup_{r=1}^{t}\left\{\Upsilon_{r}^{j} \mid \Upsilon_{r}^{j}=1\right\}\right\} \leq h-m\right)
$$

Disjointly partitioning the right-hand probability in Eqn. (21) further implies

$$
\operatorname{Prob}\left(\Delta_{i} \geq m \mid \#\left\{\cup_{r=1}^{t}\left\{\Upsilon_{r}^{i} \mid \Upsilon_{r}^{i}=1\right\}\right\}=h\right)=\prod_{j \in N \backslash i} \sum_{k=0}^{h-m} \operatorname{Prob}\left(\#\left\{\cup_{r=1}^{t}\left\{\Upsilon_{r}^{j} \mid \Upsilon_{r}^{j}=1\right\}\right\}=k\right)
$$

Combining Eqns. (19), (20), and (22), we find 


$$
P_{i}^{W}=\alpha_{i} \sum_{h=m}^{t} \operatorname{Prob}\left(\#\left\{\cup_{r=1}^{t}\left\{\Upsilon_{r}^{i} \mid \Upsilon_{r}^{i}=1\right\}\right\}=h\right) \prod_{j \in N \backslash i} \sum_{k=0}^{h-m} \operatorname{Prob}\left(\#\left\{\cup_{r=1}^{t}\left\{\Upsilon_{r}^{j} \mid \Upsilon_{r}^{j}=1\right\}\right\}=k\right)
$$

Finally, recognizing $\operatorname{Prob}\left(\#\left\{\cup_{r=1}^{t}\left\{\Upsilon_{r}^{i} \mid \Upsilon_{r}^{i}=1\right\}\right\}=h\right)$ follows the Bernoulli distribution, we obtain the desired result,

$$
P_{i}^{W}=\alpha_{i} \sum_{h=m}^{t}\left(\begin{array}{l}
t \\
h
\end{array}\right) P_{i}^{h}\left(1-P_{i}\right)^{t-h}\left[\prod_{j \in N \backslash i}\left[\sum_{k=0}^{h-m}\left(\begin{array}{l}
t \\
k
\end{array}\right) P_{j}^{k}\left(1-P_{j}\right)^{t-k}\right]\right]
$$

Using Lemma 5, we can now determine the overall probability that Player $i$ wins the contest.

Lemma 6. Define $\mathbb{P}_{i}$ as the probability that Player $i$ wins the contest. With $t$ turns in a round and a threshold potential of $m$,

$$
\mathbb{P}_{i}=\frac{\alpha_{i} \sum_{h=m}^{t}\left(\begin{array}{c}
t \\
h
\end{array}\right) g_{i}\left(x_{i}\right)^{h} \delta^{h-m}\left(1-g_{i}\left(x_{i}\right) \delta\right)^{t-h}\left[\prod_{j \in N \backslash i}\left[\sum_{k=0}^{h-m}\left(\begin{array}{c}
t \\
k
\end{array}\right) g_{j}\left(x_{j}\right)^{k} \delta^{k}\left(1-g_{j}\left(x_{j}\right) \delta\right)^{t-k}\right]\right]}{\sum_{l=1}^{n} \alpha_{l} \sum_{h=m}^{t}\left(\begin{array}{c}
t \\
h
\end{array}\right) g_{l}\left(x_{l}\right)^{h} \delta^{h-m}\left(1-g_{l}\left(x_{l}\right) \delta\right)^{t-h}\left[\prod_{j \in N \backslash l}\left[\sum_{k=0}^{h-m}\left(\begin{array}{c}
t \\
k
\end{array}\right) g_{j}\left(x_{j}\right)^{k} \delta^{k}\left(1-g_{j}\left(x_{j}\right) \delta\right)^{t-k}\right]\right]}
$$

Proof As in the proof of Lemma 6, note first that if $\sum_{l=1}^{n} P_{l}^{W} \neq 0$ then

$$
\mathbb{P}_{i}=\frac{P_{i}^{W}}{\sum_{l=1}^{n} P_{l}^{W}}
$$

Substituting Eqn. (17) into Eqn. (23) and expanding the $P_{i}$ 's per Eqn. (16),

$\mathbb{P}_{i}=$

$$
\frac{\alpha_{i} \sum_{h=m}^{t}\left(\begin{array}{c}
t \\
h
\end{array}\right) g_{i}\left(x_{i}\right)^{h} \delta^{h}\left(1-g_{i}\left(x_{i}\right) \delta\right)^{t-h}\left[\prod_{j \in N \backslash i}\left[\sum_{k=0}^{h-m}\left(\begin{array}{l}
t \\
k
\end{array}\right) g_{j}\left(x_{j}\right)^{k} \delta^{k}\left(1-g_{j}\left(x_{j}\right) \delta\right)^{t-k}\right]\right]}{\sum_{l=1}^{n} \alpha_{l} \sum_{h=m}^{t}\left(\begin{array}{c}
t \\
h
\end{array}\right) g_{l}\left(x_{l}\right)^{h} \delta^{h}\left(1-g_{l}\left(x_{l}\right) \delta\right)^{t-h}\left[\prod_{j \in N \backslash l}\left[\sum_{k=0}^{h-m}\left(\begin{array}{l}
t \\
k
\end{array}\right) g_{j}\left(x_{j}\right)^{k} \delta^{k}\left(1-g_{j}\left(x_{j}\right) \delta\right)^{t-k}\right]\right]}
$$

Factoring out $\delta^{m}$ and canceling gives the desired result.

Finally, we can use Lemma 6 to prove the following result of the paper. 
Theorem 3. Given the underlying model described in Section 1.1, the limit as $\delta$ approaches zero of the probability that Player $i$ wins the contest is the ratio-form contest success function:,

$$
\lim _{\delta \rightarrow 0} \mathbb{P}_{i}=\frac{\alpha_{i} g_{i}\left(x_{i}\right)^{m}}{\sum_{l=1}^{n} \alpha_{l} g_{l}\left(x_{l}\right)^{m}} \equiv \frac{f_{i}\left(x_{i}\right)}{\sum_{l=1}^{n} f_{l}\left(x_{l}\right)}
$$

Proof The Theorem is a direct result of taking the limit of $\mathbb{P}_{i}$ as defined in Lemma 6. In particular,

$$
\begin{aligned}
\lim _{\delta \rightarrow 0} \mathbb{P}_{i} & = \\
& \frac{\lim _{\delta \rightarrow 0} \alpha_{i} \sum_{h=m}^{t}\left(\begin{array}{l}
t \\
h
\end{array}\right) g_{i}\left(x_{i}\right)^{h} \delta^{h-m}\left(1-g_{i}\left(x_{i}\right) \delta\right)^{t-h}\left[\prod_{j \in N \backslash i}\left[\sum_{k=0}^{h-m}\left(\begin{array}{l}
t \\
k
\end{array}\right) g_{j}\left(x_{j}\right)^{k} \delta^{k}\left(1-g_{j}\left(x_{j}\right) \delta\right)^{t-k}\right]\right]}{\lim _{\delta \rightarrow 0} \sum_{l=1}^{n} \alpha_{l} \sum_{h=m}^{t}\left(\begin{array}{l}
t \\
h
\end{array}\right) g_{l}\left(x_{l}\right)^{h} \delta^{h-m}\left(1-g_{l}\left(x_{l}\right) \delta\right)^{t-h}\left[\prod_{j \in N \backslash l}\left[\sum_{k=0}^{h-m}\left(\begin{array}{l}
t \\
k
\end{array}\right) g_{j}\left(x_{j}\right)^{k} \delta^{k}\left(1-g_{j}\left(x_{j}\right) \delta\right)^{t-k}\right]\right]}
\end{aligned}
$$

The limit of the numerator equals

$$
\begin{aligned}
\lim _{\delta \rightarrow 0} \alpha_{i} \sum_{h=m}^{t}\left(\begin{array}{l}
t \\
h
\end{array}\right) g_{i}\left(x_{i}\right)^{h} \delta^{h-m}\left(1-g_{i}\left(x_{i}\right) \delta\right)^{t-h}\left[\prod_{j \in N \backslash i}\left[\sum_{k=0}^{h-m}\left(\begin{array}{l}
t \\
k
\end{array}\right) g_{j}\left(x_{j}\right)^{k} \delta^{k}\left(1-g_{j}\left(x_{j}\right) \delta\right)^{t-k}\right]\right] \\
=\alpha_{i} \sum_{h=m}^{t} \lim _{\delta \rightarrow 0}\left(\begin{array}{l}
t \\
h
\end{array}\right) g_{i}\left(x_{i}\right)^{h} \delta^{h-m}\left(1-g_{i}\left(x_{i}\right) \delta\right)^{t-h}\left[\prod_{j \in N \backslash i} \lim _{\delta \rightarrow 0}\left[\sum_{k=0}^{h-m}\left(\begin{array}{l}
t \\
k
\end{array}\right) g_{j}\left(x_{j}\right)^{k} \delta^{k}\left(1-g_{j}\left(x_{j}\right) \delta\right)^{t-k}\right]\right] \\
=\alpha_{i} \sum_{h=m}^{t} \lim _{\delta \rightarrow 0}\left(\begin{array}{l}
t \\
h
\end{array}\right) g_{i}\left(x_{i}\right)^{h} \delta^{h-m}\left(1-g_{i}\left(x_{i}\right) \delta\right)^{t-h}\left[\prod _ { j \in N \backslash i } \left[\lim _{\delta \rightarrow 0}\left(\begin{array}{l}
t \\
0
\end{array}\right) g_{j}\left(x_{j}\right)^{0} \delta^{0}\left(1-g_{j}\left(x_{j}\right) \delta\right)^{t}\right.\right. \\
\left.\left.+\lim _{\delta \rightarrow 0} \sum_{k=1}^{h-m}\left(\begin{array}{l}
t \\
k
\end{array}\right) g_{j}\left(x_{j}\right)^{k} \delta^{k}\left(1-g_{j}\left(x_{j}\right) \delta\right)^{t-k}\right]\right] \\
=\alpha_{i} \sum_{h=m}^{t} \lim _{\delta \rightarrow 0}\left(\begin{array}{l}
t \\
h
\end{array}\right) g_{i}\left(x_{i}\right)^{h} \delta^{h-m}\left(1-g_{i}\left(x_{i}\right) \delta\right)^{t-h} \\
=\alpha_{i} \lim _{\delta \rightarrow 0}\left(\begin{array}{c}
t \\
m
\end{array}\right) g_{i}\left(x_{i}\right)^{m} \delta^{0}\left(1-g_{i}\left(x_{i}\right) \delta\right)^{t-m}+\sum_{h=m+1}^{t} \lim _{\delta \rightarrow 0}\left(\begin{array}{l}
t \\
h
\end{array}\right) g_{i}\left(x_{i}\right)^{h} \delta^{h-m}\left(1-g_{i}\left(x_{i}\right) \delta\right)^{t-h} \\
=\alpha_{i}\left(\begin{array}{l}
t \\
m
\end{array}\right) g_{i}\left(x_{i}\right)^{m}
\end{aligned}
$$

where $\sum_{k=1}^{0} \equiv 0$. Using identical logic on the denominator and substituting into Eqn. (24),

$$
\begin{aligned}
\lim _{\delta \rightarrow 0} \mathbb{P}_{i} & =\frac{\alpha_{i}\left(\begin{array}{c}
t \\
m
\end{array}\right) g_{i}\left(x_{i}\right)^{m}}{\sum_{l=1}^{n} \alpha_{l}\left(\begin{array}{c}
t \\
m
\end{array}\right) g_{l}\left(x_{l}\right)^{m}} \\
& =\frac{\alpha_{i} g_{i}\left(x_{i}\right)^{m}}{\sum_{l=1}^{n} \alpha_{l} g_{l}\left(x_{l}\right)^{m}}
\end{aligned}
$$




\section{Continuous Model with Relative Threshold}

\subsection{Model}

In the continuous formulation of the relative threshold model, players again compete in a series of rounds, each of time duration, $T$. As in the discrete case, players attempt to hit targets throughout the round. If, at the end of the round, the difference between one player's number of successful hits and the second most successful player's number of successful hits weakly exceeds the threshold potential, that player has the ability to win the contest. If no player surpasses the relative threshold, the number of successful hits "resets", and a new round is played.

Formally, let $N=\{1,2, \ldots, n\}$ be the set of players who may participate in a contest. The contest consists of (potentially) multiple rounds, with each round having time duration, $T$. The rules are as follows:

1. As in the continuous model with absolute threshold, every player's number of successes follows a Poisson process. In particular, the time, $t$, at which each sequential independent success occurs is a random variable having exponential density,

$$
P_{i} \equiv g_{i}\left(x_{i}\right) \delta \exp ^{-g_{i}\left(x_{i}\right) \delta t} .
$$

As before, the probability that an individual is successful at or before time $t$ equals

$$
\int_{0}^{t} P_{i} d t=1-\exp ^{-g_{i}\left(x_{i}\right) \delta t}
$$

with $g_{i}\left(x_{i}\right)$ and $\delta$ having equivalent interpretations.

2. After the round is complete, a player is said to reach the threshold potential, $m$, if he has $m$ or more successful attempts than the second most successful player during the round. As with the discrete case, this threshold is a relative benchmark representing how much better one player must perform compared to the other players.

3. After the round is complete, if any player reaches the threshold potential, he wins the contest with probability $\alpha_{i} \in(0,1]$. This probability incorporates personal characteristics of the individual players.

4. If no player wins at the end of the round, a new round is played.

\subsection{Results}

I now show that under the continuous model with relative threshold described in Section 4.1, the limit as the technical boundary, $\delta$, approaches zero of the probability a given player wins the contest equals the ratio contest function specified in Eqn. 1. 
Lemma 7. Define $P_{i}^{W}$ as the probability that Player $i$ wins a round. With each round having time duration, $T$, and a threshold potential of $m$,

$$
P_{i}^{W}=\sum_{h=m}^{\infty} \frac{\exp ^{-g_{i}\left(x_{i}\right) \delta T} g_{i}\left(x_{i}\right)^{h} \delta^{h} T^{h}}{h !} \prod_{j \in N \backslash i} \sum_{k=0}^{h-m} \frac{\exp ^{-g_{j}\left(x_{j}\right) \delta T} g_{j}\left(x_{j}\right)^{k} \delta^{k} T^{k}}{k !}
$$

Proof Note with the defined underlying Poisson process, the probability of achieving $h$ successes in a time period of length, $T$, follows the Poisson distribution,

$$
\operatorname{Prob}(h \text { successes })=\frac{\exp ^{-g_{i}\left(x_{i}\right) \delta T} g_{i}\left(x_{i}\right)^{h} \delta^{h} T^{h}}{h !}
$$

Using this probability and following identical logic to Lemma 5 gives the desired results.

Using Lemma 7, we can now determine the overall probability that Player $i$ wins the contest.

Lemma 8. Define $\mathbb{P}_{i}$ as the probability that Player $i$ wins the contest. With each round having time duration, $T$, and a threshold potential of $m$,

$$
\mathbb{P}_{i}=\frac{\sum_{h=m}^{\infty} \exp ^{-g_{i}\left(x_{i}\right) \delta T} g_{i}\left(x_{i}\right)^{h} \prod_{j \in N \backslash i} \sum_{k=0}^{h-m} \frac{\exp ^{-g_{j}\left(x_{j}\right) \delta T} g_{j}\left(x_{j}\right)^{k} \delta^{k} T^{k}}{k !}}{\sum_{l=1}^{n} \sum_{h=m}^{\infty} \exp ^{-g_{l}\left(x_{l}\right) \delta T} g_{l}\left(x_{l}\right)^{h} \prod_{j \in N \backslash l} \sum_{k=0}^{h-m} \frac{\exp ^{-g_{j}\left(x_{j}\right) \delta T} g_{j}\left(x_{j}\right)^{k} \delta^{k} T^{k}}{k !}}
$$

Proof As in the proof of Lemma 2, note first that if $\sum_{l=1}^{n} P_{l}^{W} \neq 0$ then

$$
\mathbb{P}_{i}=\frac{P_{i}^{W}}{\sum_{l=1}^{n} P_{l}^{W}}
$$

Substituting Eqn. (25) into Eqn. (26) and canceling $\delta^{m}, T^{m}$, and $m$ ! gives the desired result.

Finally, we can use Lemma 8 to prove the final result of the paper.

Theorem 4. Given the underlying model described in Section 4.1, the limit as $\delta$ approaches zero of the probability that Player $i$ wins the contest is the ratio-form contest success function:

$$
\lim _{\delta \rightarrow 0} \mathbb{P}_{i}=\frac{\alpha_{i} g_{i}\left(x_{i}\right)^{m}}{\sum_{l=1}^{n} \alpha_{l} g_{l}\left(x_{l}\right)^{m}} \equiv \frac{f_{i}\left(x_{i}\right)}{\sum_{l=1}^{n} f_{l}\left(x_{l}\right)}
$$

As the proof follows Theorem 3 very closely, it is omitted. 


\section{Uniformly Distributed Spatial Game}

Both discrete models are especially applicable to a class of contests which contains an underlying spatial component. In particular, let $\tau$, a point on the real number line, $\Re,{ }^{15}$ signify a strategically relevant "target" that must be "hit" in order for a player to have a chance of winning the contest. In military contests, for instance, this point could be a specific tactical target. Every attempt consists of "destroying" the interval, $\left[\delta_{L}, \delta_{R}\right]$, where $\delta_{R}-\delta_{L}=\delta$. If $\tau$ is within the interval, the attempt is successful. While the location of $\tau$ is known, the ability to hit $\tau$ is imperfect. Specifically, a player can only ensure $\delta_{L}$ is located within the precision interval, $\tau_{\delta} \equiv\left[\tau-\frac{1}{2 g_{i}\left(x_{i}\right)}, \tau+\frac{1}{2 g_{i}\left(x_{i}\right)}\right]$, where $g_{i}\left(x_{i}\right)$ is the precision function defined in Section 1.1. The random location of $\delta_{L}$ within $\tau_{\delta}$ is uniformly distributed. Figure 1 represents this spatial contest.

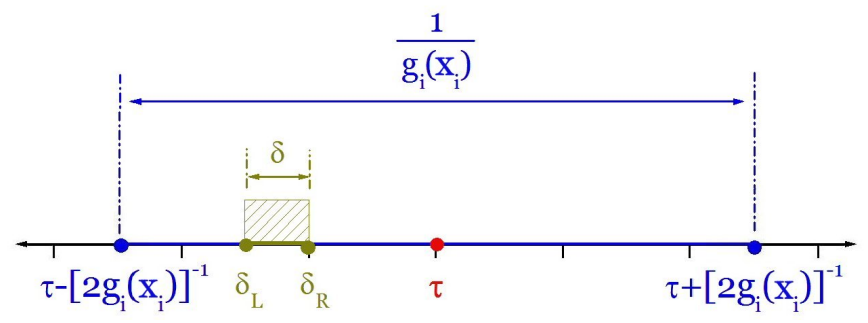

Figure 1: Spatial Contest

In this framework, $\frac{1}{g_{i}\left(x_{i}\right)}$ is the production function transforming effort into precision. In military contests, for example, this can be interpreted as the function mapping effort into weapon precision. Note the probability of hitting the target in this environment is $g_{i}\left(x_{i}\right) \delta$, as specified in the models presented in Sections 1.1 and 3.1.

\section{Examples}

\subsection{Schmalensee's Model of Advertising}

With Theorems 1-4, we find four alternate microfoundations for the ratio-form contest success function. The appropriate foundation is entirely dependent on the underlying economic interpretation. Consider, for example, Schmalensee's (1992) model of advertising, in which a company's market share is given by

$$
s_{i}=\frac{A_{i}^{m}}{\sum_{j=1}^{n} A_{j}^{m}}
$$

where $A_{i}$ is company i's advertising expenditures and there are $n$ firms in the market. Assume consumers pay attention to commercials with a small exogenous probability. The four elements making up the microfoundations can be interpreted as follows:

\footnotetext{
${ }^{15}$ Expanding the model to multiple dimensions does not change the results.
} 
Absolute Threshold: There is an advantage to being the first recognized product brand.

Relative Threshold: There is an advantage to having a comparatively easily recognizable product.

Discrete Model: Quality and creativity of advertisements are not influential. Ads are basically the same, with advertising expenditures varying the quantity of advertisements.

Continuous Model: Quality and creativity of advertisements are influential. Ads are sufficiently different, with advertising expenditures varying the quality of advertisements.

The pharmaceutical industry, for instance, would be a candidate for the absolute discrete model, in which Hurwitz and Caves (1988) find significant first-mover advantages even after patent expiration.

\subsection{Grossman's Model of Insurrections}

Consider Grossman's (1991) model of insurrections in which he examines a model in which peasant families can divide their time between production, soldiering, and participating in an insurrection. Soldiers and insurrectionists engage in conflict to determine who receives government profits. Grossman specifically assumes the probability the insurrection is successful, $\beta$, is in the form

$$
\beta=\frac{I^{1-\theta}}{S^{\sigma}+I^{1-\theta}}, 0 \leq \theta \leq 1,0<\sigma<1
$$

where $I$ is the fraction of peasant time allocated to participating in the insurrection and $S$ is the fraction of peasant time allocated to soldiering. ${ }^{16}$

Within the context of the discrete model with absolute threshold, this has a natural interpretation. In particular, assume the government and the insurrection each has a pivotal leader. Assume if the government leader is assassinated first, the insurrectionists place their leader in power. Likewise, if the insurrection leader is assassinated first, the insurrection is defeated. Assume weapon technology is such that a solider "in range" of a target still has a small likelihood of successfully killing the target. ${ }^{17}$ Also assume the government and the insurgents have access to different military technologies, so the probability of the insurgent getting in range of the government target is $I^{1-\theta}$ and the probability of the government getting in range of the insurgent target is $S^{\sigma}$. Theorem 1 implies the probability that the insurrection will be successful approaches $\beta=\frac{I^{1-\theta}}{S^{\sigma}+I^{1-\theta}}$.

Note this is not the only conflict interpretation for Grossman's CSF. An alternative interpretation is strictly spatial. Instead of assuming each side has a pivotal leader, assume each side has a pivotal physical target located at $\tau .{ }^{18}$ The strength of weapons is exogenous (and small), but the precision of the weapon can be increased via a technology of innovation. The insurgency can ensure their weapon lands within $\frac{I^{\theta-1}}{2}$ of the government's pivotal target, with the exact location of the strike

\footnotetext{
${ }^{16}$ Alternatively, $I$ can be interpreted as the percentage of peasants who are insurgents and $S$ as the percentage of peasants who are soldiers.

${ }^{17}$ In models of modern warfare, this assumption becomes suspect. However, the assumption of a continuous CSF also becomes suspect, since in many cases technology is such that victory is ensured via complete annihilation.

${ }^{18}$ Alternatively, assume each side has $m$ pivotal targets that must be hit to ensure success.
} 
a random variable uniformly distributed along the interval $\left[\tau-\frac{I^{\theta-1}}{2}, \tau+\frac{I^{\theta-1}}{2}\right]$. Likewise, the government's precision technology ensures their weapon lands within $\frac{S^{-\sigma}}{2}$ of the insurgent target. As before, the probability the insurrectionist weapon will destroy the government's pivotal target first approaches $\beta=\frac{I^{1-\theta}}{S^{\sigma}+I^{1-\theta}}$.

\subsection{Petranka's Model of Political Conflict}

Utilizing the spatial interpretation of the model is not restricted to actual physical conflict. In Petranka's (2010) model of political conflict, I consider a spatial model of voting in which voters probabilistically vote for each candidate who does not reject their ideal point. ${ }^{19}$ The voting rule follows the CSF:

$$
s_{i}\left(A_{i}\right)=\frac{\frac{\alpha_{i}}{\left(A_{i}\right)^{m}}}{\sum_{l=1}^{n} \frac{\alpha_{l}}{\left(A_{l}\right)^{m}}}, i \in\{1, \ldots, n\}
$$

where $\alpha_{i}$ represents each candidate's personal ability to sway voters, and $A_{i}$ represents the ambiguity level of each candidate. Assuming that the two candidates are competing for voters whose ideologies range from 1 to 7, as is standard in the American National Election Survey, the ambiguity level is defined as the location of the candidate's most conservative stance minus the location of his most liberal stance.

As an interpretation of this CSF, assume that once a voter determines that each candidate offers her ideal point as part of his campaign platform, she then "pays attention" to determine which candidate is more likely to follow through. Voters are imperfectly informed, and each receives her information through the news media. Assume the news media broadcasts news segments, which randomly detail a specific policy stance for a specific candidate. ${ }^{20}$ Once a given candidate is selected for discussion, the particular issue that is deemed newsworthy in any particular day is uniformly selected from the candidate's possible campaign stances. Even if a candidate is ambiguous about a certain issue, the media covers the fact that the particular issue is part of the candidate's campaign stance. Each news segment covers the issues within a policy interval of size $\delta$.

In an effort to reduce information costs, voters use a partially-informative heuristic that economizes on the effort needed to reach a decision subject to the requirement that the heuristic is "generally" correct. This coincides with the findings of Lau and Redlawsk (2006: 138) who find voters are more inclined to use heuristics when candidate ideologies are similar. Assume the specific heuristic is a satisficing heuristic, in which each voter receives information until one of the candidates has passed a certain threshold, at which point the voter makes her decision. Specifically, assume each voter watches news segments until they have observed one of the candidates espouse her ideal point $m$ more times than the other candidate times in a short enough time interval. As an illustrative (and entirely arbitrary) example, assume a pro-life voter watches the news every day, and if she hears a

\footnotetext{
${ }^{19}$ Please refer to Petranka (2010) for the specification of individual properties of the voter decision such as the rejection criteria.

${ }^{20}$ The random element of the news segments assumes a voter is watching an unbiased media report, an assumption based on the fact she is attempting to formulate a correct issue-based decision.
} 
candidate state "I am against abortion" three more times than his opponent, she will believe the candidate with probability $\alpha_{i}$ and decide to vote for that candidate. If, however, neither candidate fulfills this requirement, the voter will watch the news the next day in the hopes one of the candidates satisfies her voting requirements. Note because the voter is only receiving additional information if both candidates have not rejected her ideal point, the voter will never hear a candidate reject her stance at this point. She instead is only trying to determine which is more sincere.

Under this heuristic, for a given ideal point and candidate, the probability Candidate i's stance on the point is discussed by the news media in a given broadcast is $\frac{\delta}{A_{i}}$. Assuming each candidate is equally likely to be discussed, Theorem 3 implies the probability of a voter voting for Candidate i approaches $\frac{\frac{\alpha_{i}}{\left(A_{i}\right)^{m}}}{\sum_{l=1}^{n} \frac{\alpha_{l}}{\left(A_{l}\right)^{m}}} \cdot{ }^{21}$

\section{Competition Costs}

An important caveat to using this interpretation of the ratio-form CSF in economic models is that numerous rounds will likely be played before the contest concludes. Specifically, as $\delta \rightarrow 0$, the probability that the game ends after any $M \in \mathbb{Z}^{+}$rounds approaches 1 . Thus, if there is any nontrivial cost to participating in a round of conflict, the expected cost of the contest becomes unbounded as the technological boundary approaches zero. In some scenarios, this caveat will prove insurmountable. However, in many scenarios the cost of a round can naturally be assumed to relate to the size of $\delta$. Defining $c$ as the cost of a single round, a sufficient condition for the cost of the contest to remain finite is $\delta \rightarrow 0 \Rightarrow c \rightarrow 0$. For example, in the Petranka (2010) model, if the cost of watching a news item converges to zero as the length of time of the news item converges to zero, then as $\delta \rightarrow 0$, the expected cost of the conflict will converge to zero. In a military conflict, $\delta \rightarrow 0$ implies that weapons are not sufficiently destructive. If these nondestructive weapons are extremely cheap, ${ }^{22}$ we can again avoid having costs become unbounded.

It is useful to note this caveat and approach is similar in spirit to Binmore et al.'s (1986) justification for the Nash Bargaining solution as a limit result of Rubinstein's (1982) alternating offers game. Specifically, the alternating offers game only approaches the Nash bargaining solution if the time necessary to make an offer is very small. Likewise, the model proposed here is only valid if the cost necessary to make an attempt is very small.

\section{Conclusion}

This paper proposes a new interpretation for the ratio-form contest success function that models a contest as a game in which the players exert effort in an attempt to increase their probability of successfully performing some action. When enough successful attempts are made in a specific period, the player passes a threshold allowing him to win the full contest. As the limit of a the

\footnotetext{
${ }^{21}$ It should be noted that in Petranka (2010), I perform comparative statics on $m$, which is not appropriate in this context given the integer nature of $m$. If, instead, I assume the probability a particular issue is newsworthy is random, and each media outlet chooses to discuss Candidate i with probability $\frac{\delta}{A_{i}^{m}}$, I will find an equivalent result. This interpretation captures the concept that as politicians become more ambiguous, news stations are unwilling to attribute to them a particular issue stance.

${ }^{22}$ For instance, in contests of hunter-gather societies such as Baker (2003), it is natural that weapons are assumed to be extremely primitive.
} 
probability of a successful attempt converges to zero, the probability of winning the contest converges to the ratio-form CSF.

This approach contributes to the literature in three ways. First, if offers a justification for the ratio-form CSF in non-bargaining scenarios. While Corchón and Dahm's (2008) Nash-bargaining justification for ratio-form CSF's is extremely valid in bargaining scenarios, there exist economic scenarios that do not fall under their framework. In these cases, this alternate approach can be used when there is a small probability of success in any round, the contest cost converges to zero as the probability of success converges to zero, and a "race-to-threshold" interpretation of the underlying contest exists.

Second, my approach introduces a spatial interpretation of the ratio-form CSF. This can prove useful in modeling actual physical conflict, but also holds use for other economic applications. Using a similar framework, areas can be investigated which incorporate the concept of an ideological space with preferred ideal points. For instance, ratio-form CSF's in legal contexts such as Katz (1988) can be interpreted as lawyers competing to "hit" the ideal argument that will convince a judge/juror. If the space of possible arguments is spatial in nature, ratio-form CSF's can be justified using this approach.

Lastly, instead of viewing the effectivity function, $f_{i}\left(x_{i}\right)$, as a measure of utility as in the random utility formulation, I view it as related to an actual production function mapping effort to precision. Thus, its returns to scale has a productive meaning, and by appropriately defining the threshold limit, this production function can be given appropriate characteristics. This admits a productive interpretation of necessary axiomatic conditions imposed on effectivity functions such as those required by Rai and Sarin (2007) to induce "mixed homogeneity" in the CSF.

It is worth noting that none of the four presented models incorporates any concept of learning. Only the two extreme cases of total recall and total between-period forgetfulness are incorporated. Within the framework presented in this paper, learning cannot be incorporated, in that success in a given period will no longer be independent to success in previous periods. Whether a microfoundational learning model can be developed is an open question, but it is worth noting that the nature of the contest success function is essentially that of fixed-costs. Once effort levels are selected, the probabilities of success are established.

As a final note, this paper should be viewed as complementary to Corchón and Dahm (2008) and $\mathrm{Fu}$ and $\mathrm{Lu}$ (2008), and should be viewed as only one approach to modeling CSF's. Hopefully, additional foundations will arise justifying the use of ratio-form CSF's in scenarios where Corchón and Dahm (2008), Fu and Lu (2008), and my assumptions are not appropriate.

\section{References}

Baker, Matthew J. "An Equilibrium Conflict Model of Land Tenure In Hunter-Gatherer Societies". The Journal of Political Economy, 2003. 111, pp. 124-173.

Baye, Michael, Kovenock, Dan and Vries, Casper De. "The Solution to the Tullock RentSeeking Game when R>2: Mixed-strategy Equilibria and Mean Dissipation Rates". Public Choice, 1994. 81, pp. 363-380. 
Baye, Michael R. and Hoppe, Heidrun C. "The Strategic Equivalence of Rent-Seeking, Innovation, and Patent-Race Games". Games and Economic Behavior, 2003. 44, pp. 217-226.

Binmore, Ken, Rubinstein, Ariel and Wolinsky, Asher. "The Nash Bargaining Solution in Economic Modelling". The RAND Journal of Economics, 1986. 17(2), pp. 176-188.

Casella, George and Berger, Roger L. Statistical Inference. Duxbury Press, 2002.

Che, Yeon-Koo and Gale, Ian. "Difference-Form Contests and the Robustness of All-Pay Auctions". Games and Economic Behavior, 2000. 30, pp. 22-43.

Clark, Derek and Riis, Christian. "On the Win Probability in Rent-Seeking Games", 1996. Memorandum from Department of Economics, University of Oslo, No. 5.

Clark, Derek J and Riis, Christian. "Contest Success Functions: An Extension". Economic Theory, 1998. 11, pp. 201-204.

Corchón, Luis and Dahm, Matthias. "Foundations for Contest Success Functions", 2008. Economic Theory, Published Online: 26 November.

Dasgupta, Partha and Stiglitz, Joseph. "Uncertainty, Industrial Structure, and the Speed of R\&D". The Bell Journal of Economics, 1980. 11, pp. 1-28.

Farmer, Amy and Pecorino, Paul. "Legal Expenditures as a Rent-Seeking Game". Public Choice, 1999. 100, pp. 271-288.

Fu, Qiang and Lu, Jingfeng. "A Micro Foundation of Generalized Multi-Prize Lottery Contests: A Noisy Ranking Perspective", 2008.

Garfinkel, Michelle R. and Skaperdas, Stergios. "Conflict without Misperceptions or Incomplete Information". Journal of Conflict Resolution, Dec. 2000. 44(6), pp. 793-807.

Grossman, Herschell I. "A General Equilibrium Model of Insurrections". The American Economic Review, Sep. 1991. 81(4), pp. 912-921.

Hirshleifer, Jack. "The Analytics of Continuing Conflict". Synthese, Aug. 1988. 87, pp. 201-233.

—. "Conflict and Rent-Seeking Success Functions: Ratio vs. Difference Models of Relative Success". Public Choice, 1989. 63, pp. 101-112.

Hurwitz, Mark A. and Caves, Richard E. "Persuasion or Information? Promotion and the Shares of Brand Name and Generic Pharmaceuticals". Journal of Law and Economics, 1988. 31, pp. 299-320.

Katz, Avery. "Judicial Decisionmaking and Litigation Expenditure". International Review of Law and Economics, 1988. 8, pp. 127-143.

Kooreman, Peter and Schoonbeek, Lambert. "The Specification of the Probability Functions in Tullock's Rent-Seeking Contest". Economics Letters, 1997. 56, pp. 59-61.

Lau, Richard R. and Redlawsk, David P. How Voters Decide: Information Processing during Election Campaigns. Cambridge University Press, 2006. 
Loury, Glenn C. "Market Structure and Innovation". The Quarterly Journal of Economics, Aug. 1979. 93, pp. 395-410.

McFadden, Daniel. "Conditional Logit Analysis of Qualitative Choice Behavior". In Paul Zarembka, ed., "Frontiers in Econometrics", Academic Press, New York, 1973.

—. "The measurement of Urban Travel Demand". Journal of Public Economics, 1974. 3, pp. 303-328.

National Commission on Terrorist Attacks upon the United States. The 9/11 Commission Report: Final Report of the National Commission on Terrorist Attacks upon the United States. New York: Norton, 2004.

Perez-Castrillo, J. David and Verdier, Thierry. "A General Analysis of Rent-Seeking Games". Public Choice, 1992. 73, pp. 335-350.

Petranka, Jeremy. "A Conflict Theory of Voting", 2010. http://www. unc.edu/ petranka/Petranka_CTV.pdf.

Rai, Birendra K. and Sarin, Rajiv. "Parametric Contest Success Functions", 2007. Jena Economic Research Papers 2007-010.

—. "Generalized Contest Success Functions". Economic Theory, 2009. 40(1), pp. 139-149.

Rubinstein, Ariel. "Perfect Equilibrium in a Bargaining Model". Econometrica, 1982. 50(1), pp. 97-109.

Schmalensee, Richard. "Sunk Costs and Market Structure: A Review Article". The Journal of Industrial Economics, Jun. 1992. 40, pp. 125-134.

Skaperdas, Stergios. "Contest Success Functions". Economic Theory, 1996. 7, pp. 283-290.

Skaperdas, Stergios and Grofman, Bernard. "Modeling Negative Campaigning". The American Political Science Review, Mar. 1995. 89, pp. 49-61.

Snyder, James M. "Election Goals and the Allocation of Campaign Resources". Econometrica, May 1989. 57, pp. 637-660.

Tullock, Gordon. "On the Efficient Organization of Trials". Kyklos, 1975. 28, pp. 745-762.

- "Efficient Rent Seeking". In "Toward a Theory of the Rentseeking Society", Texas A\&M University Press, College Station, TX, 1980 pp. 97-112. 